\title{
Hubungan Pengetahuan dan Sikap Ibu Nifas dengan Pemberian ASI Ekslusif di Ruang Kasuari RSU Anutapura Palu
}

\author{
Dewi Sry Ayu, Ni Made Rosiyana*, Vira Pratiwi \\ Diploma III Kebidanan, AKBID Palu \\ *Email korespondensi: maderosiyana@gmail.com
}

\section{Article Info}

Article history:

Submitted: 2019-02-26

Accepted: 2019-04-16

Published: 2019-04-22

Keywords:

Knowledge;

Attitude;

Exclusive breastfeeding;

\section{ABSTRACT}

Breastmilk has several advantages when compared to formula milk. Breastmilk is cheap, healthy and easy to give. The provision of exclusive breastfeeding in the city of Palu increased relatively in $2015(68 \%)$ to $2016(64 \%)$. While respecting exclusive breastfeeding at Anutapura General Hospital in Palu in 2016 $(74 \%)$ or 1,462 of the total births of 1954 and not yet reaching the national target of $80 \%$. This study is an analytical study that uses Cross sectional with a sample of 48 respondents. Statistical test results from the knowledge of postpartum mothers with the help of Exclusive ASI obtained $p$ value $=1,000$ in the exact test, with a confidence level of $\alpha=0.05$, so the value of $p>\alpha$ then $\mathrm{H} 1$ is accepted and $\mathrm{HO}$ is supported, allowing statistics there is no relationship between maternal knowledge childbirth with exclusive breastfeeding. While the results of statistical tests of postpartum mothers' attitudes with exfoliated breastfeeding obtained a $p$ value $=0.009$ in Chi-square test, with a confidence level of $\alpha=$ 0.05 , so the $\mathrm{p}$ value $<\alpha$ then $\mathrm{H} 1$ was accepted and $\mathrm{H} 0$, according to statistics there was a relationship between attitudes postpartum mothers with exclusive breastfeeding. So conclusions can be drawn between no relationship between knowledge of postpartum mothers and exclusive breastfeeding and there is a relationship between postpartum maternal attitudes and the provision of exclusive breastfeeding at Anutapura Hospital Palu.

\section{PENDAHULUAN}

United Nations Internasional Childern's Emergency Fund (UNICEF) dan World Health Organitation (WHO) merekomendasikan ASI Ekslusif sampai bayi berumur 6 bulan. Penelitian menunjukan bahwa kandungan nutrien pada ASI ternyata lebih bagus bila dibandingkan dengan kandungan pada formula susu sapi ${ }^{1}$. Pengenalan dini makanan yang rendah gizi dan energi atau yang disiapkan dalam kondisi yang tidak hyigenis dapat menyebabkan anak kurang gizi dan terinfeksi organisme asing, sehingga mempunyai daya tahan tubuh yang rendah terhadap penyakit di antara anak-anak ${ }^{2}$. Studi di American Academy of Pediatrics, menunjukkan, bahwa bayi yang tidak diberi ASI memiliki tingkat kematian yang tinggi, dan tingkat lebih tinggi terkena leukemia, kelebihan berat badan dan obesitas, tingkat kolesterol serta asma ${ }^{3}$.

Keputusan Menteri Kesehatan Nomor 450/MENKES/SK/VI/2004 tentang pemberian ASI secara ekslusif di Indonesia, menetapkan ASI Ekslusif di Indonesia selama 6 bulan dan dianjurkan dilanjutkan sampai dengan anak berusia 2 tahun atau lebih dengan pemberian makanan tambahan yang sesuai. ${ }^{2}$ Pemberian ASI Eksklusif dapat menekan AKB dengan mengurangi sebesar 30.000 kematian bayi di Indonesia dan 10 juta kematian bayi di dunia melalui pemberian ASI Eksklusif selama 6 bulan sejak jam pertama kelahirannya tanpa memberikan makanan dan minuman 
tambahan kepada bayi. ${ }^{4}$

Tingkat pengetahuan ibu yang kurang tentang pemberian ASI mengakibatkan bayi lebih sering diberi susu botol dari pada disusui ibunya, dan sikap ibu yang salah dalam pemberian makanan tambahan sebelum bayi berusia 6 bulan yang sudah di beri pisang saat bayi baru berusia 1 bulan. ${ }^{5}$ Sedangkan dari hasil penelitian yang dilakukan oleh Situngkir dan Siahaan, 2014 menemukan bahwa 53\% responden memiliki sikap kurang mendukung pemberian ASI Ekslusif. ${ }^{6}$

Pemberian ASI Ekslusif di Kota Palu relatif mengalami penurunan dari tahun 2015 (68\%) ke tahun 2016 (64\%). ${ }^{7}$ Sedangkan pencapaian ASI Ekslusif di Rumah Sakit Umum Anutapura Palu pada tahun 2016 cakupan pemberian ASI Ekslusif 74\% atau 1.462 dari total kelahiran 1.954 dan belum mencapai target nasional yaitu $80 \%{ }^{8}$ Tujuan penelitian ini adalah untuk mengetahui hubungan pengetahuan dan sikap ibu nifas dengan pemberian ASI Ekslusif.

\section{METODE PENELITIAN}

Penelitian ini merupakan jenis penelitian analitik yang menggunakan pendekatan cross sectional. Metode analitik yang digunakan untuk mengukur hubungan antara pengetahuan dengan sikap ibu nifas terhadap pemberian ASI Ekslusif. Penelitian ini dilaksanakan pada bulan 31 Juli 2017- 5 Agustus 2017. Lokasi Penelitian telah dilaksanakan di Ruang Kasuari Bawah RSU Anutapura Palu.

Populasi dalam penelitian ini adalah pasien post partum yang dirawat inap di Ruangan Kasuari Bawah RSU Anutapura Palu pada bulan 31 Juli - 5 Agustus 2017. Sedangkan sampel pada penelitian ini adalah 48 ibu nifas dengan teknik sampel dalam Accidental Sampling yaitu dilakukan pada ibu yang mempunyai bayi 0-6 bulan di RSU Anutapura Palu.

Data ada penelitian ini terdiri dari dua data yaitu data primer dan data sekunder. Data primer pada penelitian ini berupa data pengetahuan dan data sikap yang dikumpulkan menggunakan kuesioner, untuk kusioner sikap terdiri dari 12 pertanyaan (6 pertanyaan positif dan 6 pertanyaan negatif), sedangkan untuk kuesioner sikap terdiri dari 10 pernyataan. Sedangkan data sekunder pada peneltian ini diperoleh dari laporan atau catatan laporan hasil cakupan ibu nifas yang menyusui di RS Anutapura Palu.

Dalam penelitian dilakukan pengolahan data dengan cara: mengedit data (editing data), memberi kode (coding data), coding data, memberi nilai (scoring skor), memasukkan (entry), mentabulasi data (tabulating data), dan cleaning.

Analisa data dalam penelitian ini menggunakan analisa univariat untuk setiap variabel dan analisa bivariat menggunakan Uji Chi Square $\left(x^{z}\right)$, untuk mengetahui hubungan antara variabel. Setelah data dianalisa maka hasil disajikan dalam bentuk tabel dan narasi.

\section{HASIL PENELITIAN}

Hasil pengelolahan data disajikan dalam analisis data univariat dan bivariat untuk mengetahui hubungan pengetahuan dan sikap ibu nifas dengan pemberian ASI ekslusif di Ruangan Kasuari Bawah Rumah Sakit Anutapura Palu yaitu sebagai berikut: 


\section{Hasil Analisa Univariat}

Tabel 1. Distribusi Pengetahuan dan Sikap Ibu Nifas di Ruangan Kasuari Bawah Rumah Sakit Anutapura Palu

\begin{tabular}{lcc}
\hline Pengetahuan & Frekuensi & Persentase (\%) \\
\hline Tinggi & 43 & 89,6 \\
Rendah & 5 & 10,4 \\
Sikap & 44 & 91,7 \\
Baik & 4 & 8,3 \\
Kurang baik &
\end{tabular}

Berdasarkan tabel 1 di atas responden dengan pengetahuan tinggi 43 (89,6\%) orang dan pengetahuan rendah $5(10,4 \%)$ orang. Menurut sikap, Baik 44 $(91,7 \%)$ orang. Responden dengan sikap kurang baik $4(8,3 \%)$ orang.

\section{Hasil Analisa Bivariat}

Tabel 2. Hubungan Pengetahuan dan Sikap Ibu Nifas dengan Pemberian ASI Ekslusif di Ruang Kasuari Bawah Rumah Sakit Umum Anutapura Palu

\begin{tabular}{lrrrrr}
\hline \multirow{2}{*}{ Variabel } & \multicolumn{4}{c}{ Pemberian ASI eksklusif } & \multirow{2}{*}{ P value } \\
\cline { 2 - 5 } & \multicolumn{2}{c}{ Ya } & \multicolumn{2}{c}{ Tidak } & \\
\cline { 2 - 5 } & $\mathrm{f}$ & $\%$ & \multicolumn{1}{c}{$\mathrm{c}$} & $\%$ & \\
\hline $\begin{array}{l}\text { Pengetahuan } \\
\quad \text { Tinggi }\end{array}$ & 29 & 67,5 & 14 & 32,5 & \\
$\quad$ Rendah & 3 & 60,0 & 2 & 40,0 & \multirow{2}{*}{1,000} \\
Sikap & & & & & \\
$\quad$ Baik & 32 & 72,8 & 12 & 27,2 & \\
$\quad$ Kurang Baik & 0 & 0,0 & 4 & 100 & 0,009 \\
\hline$\quad$ Jumlah & 32 & 66,7 & 16 & 33,3 & \\
\hline
\end{tabular}

Sumber : Data Primer 2017

Berdasarkan tabel 2 diketahui bahwa dari 48 responden terdapat 43 responden yang memiliki pegetahuan tinggi dan ada $29(67,5 \%)$ responden yang memberikan ASI Ekslusif serta ada 14 (32,5\%) responden yang tidak memberikan ASI Ekslusif. Sedangkan yang berpengethuan rendah ada 5 responden dan ada $3(60,0 \%)$ responden yang memberikan ASI ekslusif serta 2 $(40,0 \%)$ responden yang tidak memberikan ASI ekslusif.

Berdasarkan tabel 2 diketahui bahwa dari 48 responden terdapat 44 $(91,7 \%)$ responden yang memiliki sikap baik dan $32(72,8 \%)$ responden memberikan ASI Ekslusif serta $12(27,2 \%)$ responden yang tidak memberikan ASI Ekslusif.sedangkan responden yang memiliki sikap kurang baik ada 4 $(8,3 \%)$ responden dan semuanya tidak ada yang memberikan ASI Ekslusif.

\section{PEMBAHASAN}

Berdasarkan hasil uji statistik dari pengetahuan ibu nifas dengan pemberian ASI ekslusif diperoleh $p$-value $=1,000$, dengan tingkat kepercayaan $\alpha=0,05$, sehingga p-value $>\alpha$ maka $\mathrm{H}_{1}$ diterima dan $\mathrm{H}_{0}$ ditolak, berarti secara statistik tidak ada hubungan antara pengetahuan ibu nifas dengan pemberian ASI Ekslusif. Sedangkan 
hasil uji statistik dari sikap ibu nifas dengan pemberian ASI Eksluisf diperoleh nilai $p$ value $=0,009$, dengan tingkat kepercayaan $\alpha=0,05$, sehingga $p$-value $<\alpha$ maka $\mathrm{H}_{1}$ diterima dan $\mathrm{H}_{0}$ ditolak, berarti secara statistik ada hubungan antara sikap ibu nifas dengan pemberian ASI Ekslusif. Jadi dapat ditarik kesimpulan bahwa tidak ada hubungan antara pengetahuan ibu nifas dengan pemberian ASI Ekslusif dan terdapat hubungan antara sikap ibu nifas dengan pemberian ASI Ekslusif di RSU Anutapura Palu.

Menurut asumsi peneliti, tidak adanya hubungan pengetahuan dan pemberian ASI Ekslusif, disebabkan karena $89,6 \%$ responden berpengetahuan tinggi dan semua respondenberdomisili di kota sehingga mempermudah responden untuk memperoleh informasi dari media cetak maupun elektronik, dan penyuluhan tentang ASI Ekslusif oleh petugas kesehatan. Oleh karena itu, pemahaman tentang ASI Ekslusif menjadi lebih baik, dengan berbagai informasi, maka responden dapat mengetahui dan memahami suatu hal dengan benar. Hal ini dapat dilihat dari banyaknya pernyataan yang dijawab benar oleh responden pada kuesioner.

Sikap responden baik dikarenakan sering mendapat nasehat atau pengalaman, penyuluhan tentang ASI dan seluk beluknya dari orang lain, maupun dari buku buku bacaan dapat mempengaruhi sikapnya pada saat ibu tersebut harus menyusui. Sebagian besar sikap seseorang dipengaruhi oleh pengetahuan yang dipunyainya dan ia akan memberikan sikap positif terhadap ASI, jika pengetahuan tentang hal itu baik lbu yang berhasil menyusui anak sebelumnya dengan pengetahuan dan pengalaman cara pemberian ASI secara baik dan benar sehingga menunjang laktasi berikutnya. Sedangkan responden yang mempunyai sikap kurang baik disebabkan kurang mendapat nasehat, penyuluhan tentang pentingnya ASI Ekslusif, serta lingkungan dan sosial keluarga yang masih beranggapan bahwa memberikan ASI Ekslusif dapat membuat payudara kendor.

Berdasarkan analisa bivariat ibu yang berpengetahuan tinggi memiliki sikap yang baik lebih banyak dibandingkan dengan sikap ibu yang kurang baik tentang ASI Ekslusif. Sedangkan ibu yang berpengetahuan rendah memiliki sikap yang kurang baik lebih banyak sebanding dengan sikap yang baik tentang ASI Ekslusif.

Hasil penelitian ini sesuai dengan pendapat Notoatmodjo, 2012 bahwa pengetahuan merupakan hasil dari tahu dan ini terjadi setelah orang melakukan penginderaan terhadap suatu objek tertentu. Pengetahuan atau kognitif merupakan domain yang sangat penting untuk terbentuknya tindakan seseorang. Penginderaan terjadi melalui panca indra manusia, yaitu penglihatan, pendengaran, penciuman, rasa dan raba terhadap suatu hal membutuhkan suatu proses. ${ }^{9}$

Selain itu, banyak ibu/responden yang lebih memilih memberikan ASI Ekslusif karena pengetahuan mereka tentang ASI, pemberian maupun manfaatnya lebih baik. Mereka berfikir bahwa ASI memiliki banyak manfaat dan efektif serta mudah dalam memberikan pada bayinya. Penelitian ini kurang sejalan dengan banyak penelitian lainnya yang menyatakan bahwa ada hubungan antara pengetahuan ibu dengan pemberian ASI eksklusif. ${ }^{10-15}$

Hasil penelitian ini sejalan dengan teori Roesli, (2010), yang menemukan bahwa makanan bagi bayi terutama 6 bulan pertama adalah ASI, tidak ada yang bisa menggantikan nutrisi ASI bagi bayi, semahal apapun susu formula. ${ }^{5} \mathrm{ASI}$ unik karena setiap ibu akan menghasilkan ASI yang berbeda, sesuai dengan kebutuhan bayinya. Tingkat pengetahuan ibu yang kurang tentang pemberian ASI mengakibatkan bayi lebih sering diberi susu botol dari pada disusui ibunya, dan sikap ibu yang salah dalam pemberian makanan tambahan sebelum bayi berusia 6 bulan yang sudah di beri pisang saat bayi baru berusia 1 bulan. 


\section{SIMPULAN DAN SARAN}

Berdasarkan hasil penelitian ini dapat disimpulkan bahwa tidak ada hubungan pengetahuan ibu nifas dengan pemberian ASI dan ada hubungan sikap ibu nifas dengan pemberian ASI ekslusif di RSU Abutapura Palu. Diharapkan kepada petugas kesehatan untuk mengadakan konseling tentang ASI ekslusif kepada setiap ibu yang melakukan ANC, tentang pentingnya kolostrum serta manfaat dan tujuan dari ASI ekslusif, agar responden dengan sikap kurang lebih memahami tentang ASI ekslusif, dan mengubah sikap. Dengan mengadakan konseling diharapkan akan mempengaruhi ibu dan dapat mengubah sikapnya.

\section{DAFTAR PUSTAKA}

1. Proverawati A, Rahmawati E. Kapita Selekta ASI dan Menyusui. Yogyakarta: Nuha Medika; 2010.

2. Infodatin. Cakupan Pemberian ASI Ekslusif. Jakarta; 2014.

3. Maryunani A. Inisiasi Menyusui Dini, ASI Ekslusif, dan Manajemen Laktasi. Jakarta: Trans Info Media; 2012.

4. Badan Koordinasi Keluarga Berencana Nasional, Badan Pusat Statistik, Kementerian Kesehatan R.I. Survei Demografi dan Kesehatan Indonesia 2012. Jakarta; 2012.

5. Roesli U. Mengenal ASI Ekslusif. Jakarta: Trubos Agriwidya; 2010.

6. Situngkir D, Siahaan G. Hubungan Pengetahuan Dan Sikap Ibu Nifas Dengan Pemberian Asi Kolostrum Pada Bayi Baru Lahir Di Wilayah Kerja Puskesmas. Sci J [Internet]. 2014;3(2):56-61. Tersedia pada: http://ejournal.unaja.ac.id/index.php/SCJ/article/download/346/296

7. Dinas Kesehatan Kota Palu. Profil Kesehatan Sulawesi Tengah tentang Cakupan Pemberian ASI Ekslusif. Palu; 2016.

8. Rumah Sakit Umum Anutapura. Profil Kesehatan RSU Anutapura Palu tentang Cakupan Pemberian ASI Ekslusif. Palu; 2016.

9. Notoatmodjo S. Promosi Kesehatan Teori dan Aplikasi. Jakarta: PT Rineka Cipta. Jakarta: Rineka Cipta; 2012.

10. Fartaeni F, Pertiwi FD, Avianty I. Hubungan Pengetahuan, Sikap, dan Dukungan Suami terhadap Pemberian Asi Eksklusif di Desa Pabuaran Kecamatan Gunung Sindur [Internet]. Vol. 6, HEARTY. LPPM Universitas Ibn Khaldun Bogor; 2018. Tersedia pada: http://dx.doi.org/10.32832/hearty.v6i1.1255

11. Sukarini LP. Pengetahuan dan Sikap Ibu dengan Pemberian ASI Eksklusif [Internet]. Vol. 5, Jurnal Genta Kebidanan. Politeknik Kesehatan Kartini Bali; 2015. Tersedia pada: http://dx.doi.org/10.36049/jgk.v5i2.58

12. Yanuarini TA, Rahayu DE, Prahitasari E. Hubungan Pengetahuan Dengan Sikap Ibu dalam Pemberian ASI Eksklusif di Wilayah Kerja Puskesmas Pranggang Kabupaten Kediri [Internet]. Vol. 3, Jurnal IImu Kesehatan. Akademi Keperawatan Dharma Husada Kediri; 2017. hal. 1. Tersedia pada: http://dx.doi.org/10.32831/jik.v3i1.39

13. Ariani A, Rusmil K, Yuniati T. Hubungan Pengetahuan, Sikap, dan Dukungan Unit Kerja/Departemen dengan Pemberian Air Susu Ibu Eksklusif pada Tenaga Kesehatan Rumah Sakit Hasan Sadikin [Internet]. Vol. 18, Sari Pediatri. Paediatrica Indonesiana Indonesian Pediatric Society; 2016. hal. 45. Tersedia pada: http://dx.doi.org/10.14238/sp18.1.2016.45-49

14. Juliani S, Arma N. Hubungan Pengetahuan, Sikap, Dan Dukungan Tenaga Kesehatan Dengan Keberhasilan ASI Eksklusif Di Wilayah Kerja Puskesmas Darussalam Kecamatan Medan Petisah [Internet]. Vol. 1, Jurnal Bidan Komunitas. Institut Kesehatan Helvetia; 2018. hal. 115. Tersedia pada: http://dx.doi.org/10.33085/jbk.v1i3.3979

15. Pitaloka DA, Abrory R, Pramita AD. Hubungan antara Pengetahuan dan Pendidikan Ibu dengan Pemberian ASI Eksklusif di Desa Kedungrejo Kecamatan Waru Kabupaten Sidoarjo [Internet]. Vol. 2, Amerta Nutrition. Universitas Airlangga; 2018. hal. 265. Tersedia pada: http://dx.doi.org/10.20473/amnt.v2i3.2018.265-270 